\title{
Differences in soluble COD and ammonium when applying ultrasound to primary, secondary and mixed sludge
}

\author{
L. Negral*, E. Marañón, L. Castrillón, Y. Fernández-Nava \\ Department of Chemical and Environmental Engineering, University Institute of \\ Industrial Technology of Asturias, Campus of Gijón, University of Oviedo, 33203 Gijón, \\ Spain
}

*Corresponding Author: Tel: +34 985182385, fax: +34 985182337

E-mail address: negralluis@uniovi.es

\begin{abstract}
Ultrasound treatment is often applied to enhance the anaerobic digestion of sludge. Optimal conditions for organic matter solubilisation of primary, secondary and mixed sludge were assessed by implementing ultrasound disruption at different specific energies (from 3,500 to $21,000 \mathrm{~kJ} / \mathrm{kgTS}$ ). The variation in soluble chemical oxygen demand (sCOD) and ammonium nitrogen $\left(\mathrm{NH}_{4}{ }^{+} \mathrm{N}\right)$ was monitored following the treatment and after a subsequent fermentation $\left(24\right.$ hours, $\left.37^{\circ} \mathrm{C}\right)$. The effect of the treatment was clearly more pronounced in secondary sludge than in the other types of sludge. Relatively minimum values in solubility were found when applying ultrasound at different energies depending on the sludge $(3,500-7,000 \mathrm{~kJ} / \mathrm{kgTS}$ in primary sludge and $10,500-14,000 \mathrm{~kJ} / \mathrm{kgTS}$ in secondary sludge). This minimum was not so noticeable in mixed sludge. The addition of inoculum was not required after ultrasound disruption to perform the subsequent fermentation. After this final stage, no general pattern in terms of SCOD was observed. Increases and decreases were conditioned by the coverage of the ultrasound irradiation. $\mathrm{NH}_{4}{ }^{+} \mathrm{N}$ values increased notably during the fermentation.
\end{abstract}

\section{KEYWORDS}

Ammonium, COD, mixed sludge, primary sludge, secondary sludge, ultrasound 


\section{INTRODUCTION}

At a conventional wastewater treatment plant (WWTP), the settleable suspended matter is removed resulting in "primary" sludge, with a concentration of total solids (TS) in the 1-3\% range. The water line flows into the bioreactor, where microbial respiration produces "secondary" sludge (0.5-1.5\% TS) rich in microorganisms and their extracellular polymeric substances (EPS). After thickening, both types of sludge are frequently mixed, constituting what is known as "mixed" sludge (3-8\% TS). The proportion of primary and secondary sludge is expected to determine the properties of mixed sludge. However, the former undergo thickening processes for a certain period of time and hence not all the characteristics of mixed sludge are a clear combination of those of primary and secondary sludge. The characterisation of a type of sludge helps wastewater engineers to choose an affordable and suitable form of handling. Sludge management is considered a critical step because of the high-budget demand (Kavitha et al. 2014). Technical progress has assumed this precept, launching novel strategies in composting, aerobic digestion and anaerobic digestion (Tchobanoglous et al. 2014). The lower costs of the microbiological alternatives compared to other technologies often make them interesting to industry (Hasegawa et al. 2000). As regards biological implementation, the bioavailability of nutrients is an essential factor (Appels et al. 2008). Sewage sludge has been successfully used as a source of carbon for microorganisms that perform denitrification (Ucisik \& Henze 2008). However, the "occlusion" of nutrients in cell structures requires their release by means of an effective treatment applied to the microbial networks. Likewise, accelerating the hydrolysis step (which constitutes the rate-limiting step in anaerobic digestion of sewage sludge) by applying a treatment aids the anaerobic sequence (Appels et al. 2008).

The treatments employed to release the microbiological material in sludge may be physical, chemical, biological or combinations thereof (Carrère et al. 2010; Uma Rani et al. 2012a). The application of a physical treatment like ultrasound to sewage sludge transforms electrical power into mechanical energy. This mechanical energy supplied by a sonotrode results in cavitation due to bubble collapse which affects the medium (Erden \& Filibeli 2010). As extreme local conditions are caused, radicals and oxidising species appear (e.g. $\mathrm{OH} \cdot, \mathrm{HO}_{2} \cdot, \mathrm{H} \cdot$ and $\mathrm{H}_{2} \mathrm{O}_{2}$ ). An increase in temperature is therefore inherent to ultrasound disruption due to these species, shear forces and friction generated in the medium. One advantage of ultrasound treatment is the feasibility of its implementation by means of an ultrasonicator, the Specific Energy $\left(E_{s}\right)$ to apply being a key factor. Ultrasound irradiation may be technically expressed in different ways, although $E_{s}$ is the term generally employed (Pilli et al. 2011). The optimum $E_{s}$ should be related to the purpose of the treatment, whether this be increased solubilisation of organic matter (Zhang et al. 2007), enhanced methane production (Luste \& Loustarinen 2011), or further post-processing of the substrate, e.g. dewatering (Erden \& Filibeli 2010; Devlin et al. 2011). There are several reasons explaining the advantages of ultrasonication for the promotion of methane production by microorganisms: 1) Bacterial walls become flawed and permeability to monomers is increased. Even microbiological metabolism is promoted at low-intensity ultrasound implementation 
(Xie et al. 2009). 2) Ultrasound leads to the breakdown of EPS, converting them into an available substrate for bacteria (Nabarlatz et al. 2010). 3) The levels of $E_{s}$ make ultrasound disruption selective for bacterial cultures (More \& Ghangreakar 2010). Whereas a low $E_{s}$ promotes methane production, a high $E_{s}$ worsens the yield. $A$ threshold seems to appear, above which, methane production decreases. If the purpose of the treatment is to promote hydrolysis, this is achieved at low $E_{s}$. Kim \& Lee (2012) observed that the excessive hydrolysis of waste activated sludge (i.e. 50\%) caused by ultrasound irradiation led to poorer anaerobic performance. This response was probably due to partial transformation of volatile solids into inhibitory and/or inert compounds.

The success of the treatments may be measured through the solubilisation of organic matter, with soluble chemical oxygen demand (SCOD) and ammonium nitrogen $\left(\mathrm{NH}_{4}{ }^{+}-\mathrm{N}\right)$ being considered suitable indicators. The ratio of organic matter filtered (the soluble fraction) to total organic matter (the total Chemical Oxygen Demand, tCOD) was used to estimate the ease with which bacteria can overcome the steric inaccessibility of particulate organic matter (Eskicioglu et al. 2006). $\mathrm{NH}_{4}{ }^{+}-\mathrm{N}$, on the other hand, is the product of degradation of nitrogen present in macromolecules such as proteins (Broderick 1987). Thus, evaluation of ammonia can be used to monitor sludge solubilisation. This also supposes an example of inorganic species solubilisation by ultrasound treatment (Tyagi et al. 2014). Both parameters (the sCOD/tCOD ratio and $\mathrm{NH}_{4}{ }^{+}-\mathrm{N}$ ) have accordingly been used to assess this type of hydrolysis (Negral et al. 2013). Although the literature contains many studies on the hydrolysis of secondary sludge, mainly on biomethanisation (Appels et al. 2008), papers discussing the effect of applying treatments to primary and mixed sludge are scarce. This is relevant in terms of refining the selection criteria for the fractions that should be treated and to what degree. King \& Forster (1990) studied EPS extraction by ultrasound disruption of flocs; however, they described a subsequent re-flocculation phenomenon. Mao et al. (2004) observed that primary sludge was more easily solubilised, while Tyagi et al. (2014) reported that ultrasound application produced more disintegration in secondary sludge than in primary and mixed sludge. The latter finding could possibly be explained by the barrier of deflocculation in secondary sludge that must be overcome before cellular lysis (Gayathri et al. 2015). Moreover, the need to interrupt the hydrolysis step may arise if the hydrolysate is intended to be used as a carbon source in other processes (Salsabil et al. 2009). This explains the interest in presenting the results of an optimisation of hydrolysis for each type of sludge. In this context, the aims of this paper are to: a) promote hydrolysis in the three aforementioned types of sludge by applying ultrasound disruption; b) determine and compare the optimal conditions for solubilisation of the different types of sludge produced at a WWTP; and c) assess the evolution of short-term hydrolysis after applying fermentation subsequent to ultrasound disruption.

\section{MATERIALS AND METHODS Materials}

Experiments were carried out with fresh sludge from a WWTP with an average flow rate of $21,600 \mathrm{~m}^{3} /$ day $(85,000$ population equivalent $)$, removal efficiencies of $>85 \%$ 
suspended solids (SS) and $>90 \% 5$-day biochemical oxygen demand $\left(\mathrm{BOD}_{5}\right)$. The plant operates in a conventional manner with production of mixed sludge as a mixture of primary and secondary sludge. It is located in Asturias, a coastal region in the north of Spain. Primary sludge is thickened by gravity and secondary sludge, by flotation. All sludge samples were taken prior to dewatering and were grouped by type of sludge (Table 1).

\section{Equipment employed}

The ultrasound equipment was a Hielscher UP400S. This system operates at $24 \mathrm{kHz}$, with a maximum power of $400 \mathrm{~W}$, pulse adjustable to $0-100 \%$, and is equipped with an $\mathrm{H} 22$ titanium sonotrode with a $22 \mathrm{~mm}$ tip diameter. The system treated up to 2 litres in each run.

Table 1. Characterisation of initial sludge samples (mean+standard deviation)

\begin{tabular}{|c|c|c|c|c|c|c|c|c|c|}
\hline Sample & $\begin{array}{l}\mathrm{sCOD} \\
(\mathrm{mg} / \mathrm{L}) \\
\end{array}$ & $\begin{array}{l}\mathrm{tCOD} \\
(\mathrm{mg} / \mathrm{L}) \\
\end{array}$ & $\mathrm{sCOD} / \mathrm{tCOD}$ & $\begin{array}{l}\mathrm{NH}_{4}{ }^{+}-\mathrm{N} \\
(\mathrm{mg} / \mathrm{L}) \\
\end{array}$ & $\begin{array}{l}\mathrm{TS} \\
(\mathrm{g} / \mathrm{L}) \\
\end{array}$ & $\begin{array}{l}V S \\
(\mathrm{~g} / \mathrm{L}) \\
\end{array}$ & VS/TS & $\begin{array}{l}\mathrm{tCOD} / \mathrm{VS} \\
(\mathrm{g} / \mathrm{L}) /(\mathrm{g} / \mathrm{L})\end{array}$ & $\mathrm{pH}$ \\
\hline P1* & $791 \pm 158$ & $12,283 \pm 503$ & 0.06 & $29 \pm 0$ & $17.00 \pm 0.17$ & $10.01 \pm 0.18$ & 0.59 & 1.23 & 6.8 \\
\hline P2 & $6,597 \pm 174$ & $50,368+911$ & 0.13 & $136 \pm 2$ & $37.78 \pm 0.74$ & $26.72 \pm 0.40$ & 0.67 & 1.89 & n.a. \\
\hline P3 & $940 \pm 2$ & $48,501 \pm 323$ & 0.02 & $17 \pm 0$ & $59.03 \pm 0.21$ & $36.02 \pm 0.16$ & 0.61 & 1.35 & 5.7 \\
\hline P4 & $1,013 \pm 13$ & $60,884 \pm 1,414$ & 0.02 & $38 \pm 3$ & $78.40 \pm 0.31$ & $43.00 \pm 0.10$ & 0.55 & 1.42 & 5.5 \\
\hline S1 & $56 \pm 5$ & $24,933 \pm 815$ & $<0.01$ & $6 \pm 0$ & $31.94 \pm 1.65$ & $21.92 \pm 1.17$ & 0.69 & 1.14 & 6.7 \\
\hline S2 & $185+55$ & $42,104+4,138$ & $<0.01$ & $5 \pm 0$ & $45.27 \pm 0.29$ & $31.06+0.31$ & 0.69 & 1.36 & 6.5 \\
\hline S3 & $51 \pm 13$ & $39,339 \pm 2,712$ & $<0.01$ & $10 \pm 1$ & $47.55 \pm 0.07$ & $32.21 \pm 0.13$ & 0.68 & 1.22 & 6.7 \\
\hline M1 & $5,236 \pm 50$ & $47,903 \pm 1,494$ & 0.11 & $369 \pm 3$ & $39.76 \pm 0.10$ & $27.43 \pm 0.08$ & 0.69 & 1.75 & 6.0 \\
\hline M2 & $4,270 \pm 199$ & $40,732 \pm 1,629$ & 0.10 & $330 \pm 9$ & $35.29 \pm 0.15$ & $23.19 \pm 0.09$ & 0.66 & 1.76 & 6.2 \\
\hline M3 & $3,776 \pm 73$ & $45,333 \pm 1,346$ & 0.08 & $263 \pm 3$ & $47.05 \pm 0.11$ & $30.17 \pm 0.08$ & 0.64 & 1.50 & 6.0 \\
\hline
\end{tabular}

P: primary sludge; S: secondary sludge; M: mixed sludge; n.a.: not available

*: This sample was collected prior to thickening

\section{Experimental procedure}

Hydrolysis was monitored by measuring the sCOD and $\mathrm{NH}_{4}{ }^{+}-\mathrm{N}$ after each ultrasound irradiation and after 24 hours of fermentation at $37 \circ$. . No addition of inoculum was required for the fermentation stage to occur. Values for " $\mathrm{NH}_{4}{ }^{+}-\mathrm{N}^{\prime}$ in this manuscript represent the nitrogen concentration measured as the $\mathrm{NH}_{4}{ }^{+}$form. Total COD was determined as complementary information.

Total COD, soluble COD, $\mathrm{NH}_{4}{ }^{+}-\mathrm{N}$, total solids (TS), volatile solids (VS) and $\mathrm{pH}$ were determined following the Standard Methods for the Examination of Water and Wastewater (APHA 1998), as in a previous paper (Marañón et al. 2013). All analytical determinations were performed in triplicate.

All sludge samples were characterised on reception at the laboratory. In order to work with sludge as fresh as possible, each trial was completed before beginning a new test. 
Thus each sample was taken on a different date from the others. Samples were kept in a refrigerator at $4 \stackrel{\circ}{ } \mathrm{C}$ for a maximum of 1 day before applying the treatment.

Ultrasound disruption was applied to three samples of secondary and mixed sludge and to four samples of primary sludge due to the differences found in its solid content. In line with previous research (Negral et al. 2013), five energy inputs were assayed per sludge sample: 3,500 (<1-4 minutes), 7,000 (2-7 min), 10,500 (3-13 min), 14,000 (4-20 $\mathrm{min}$ ) and $21,000 \mathrm{~kJ} / \mathrm{kgTS}(6-34 \mathrm{~min})$. The specific energy $\left(E_{s}\right)$ applied to the sludge was calculated as:

$\mathrm{E}_{\mathrm{s}}[\mathrm{kJ} / \mathrm{kgTS}]=\mathrm{Pt} / \mathrm{V} \mathrm{TS}$

where $\mathrm{P}=$ ultrasound power, $\mathrm{t}=$ time of exposure of the sample to ultrasound, $\mathrm{V}=$ volume of the sample treated, and $\mathrm{TS}_{0}=$ initial total solids

The temperature of the sludge sample was measured after ultrasonication. A $200 \mathrm{ml}$ sludge aliquot was employed in every assay, always performing a blank test for the sake of comparison.

\section{RESULTS AND DISCUSSION}

The results in Table 1 show that the values of the typical physicochemical parameters fall within the usual range found for secondary and mixed sludge (Tchobanoglous et al. 2014). The greatest variability was found for primary sludge, even beyond the expected differences between the thickened samples and the unthickened sample (i.e. P1). This finding may be explained by two facts: the WWTP receives influent sewage from a combined sewer, and samples were taken in late spring/early summer, when rainfall is highly variable in the Atlantic climate region where the plant is located.

Tables 2-4 present the variations in tCOD and the SCOD/tCOD ratio with respect to their initial values after ultrasound disruption and after 24 hours of further fermentation at 37 ㅇ․ As the interest in any treatment lies in the disintegration/solubilisation of the raw material (Barjenbruch \& Kopplow 2003), Figure 1 shows the evolution in the concentrations of $S C O D$ versus the applied $E_{s}$ just after ultrasonication and subsequent fermentation.

One aspect to be taken into consideration in this treatment is the solids content of the sludge. Although the use of the $E_{s}$ applied to the substrate enables normalisation of the sludge in terms of its solids content, this content is described as a key factor for optimising the treatment (Carrère et al. 2010; Pilli et al. 2011). The yield of ultrasound disruption is limited by the physical properties of the fluid to be treated. For instance, sludge containing high levels of solids supposes a problem, making ultrasonication of this concentrated fluid unfeasible. Ultrasonication of sludge with a high solids content is unsatisfactory because of the hindering effects of cavitation (Carrère et al. 2010). Moreover, the optimum solids content reported by Show et al. (2007) does not match 
the optimum for hog manure found by Elbeshbishy et al. (2011). The latter authors reported that increasing TS up to $9 \%$ in hog manure was more effective than in primary and waste activated sludge. As the best $E_{s}$ remains within a broad range strongly dependent on the substrate and its characteristics, the optimum solids content thus seems to be substrate specific (Show et al. 2007; Negral et al. 2013).

\section{Primary sludge}

sCOD can be seen to increase with increasing $E_{s}$ (Figure 1). Three out of the four samples are seen to behave in a unique manner, presenting a more or less pronounced inflexion point in solubility after $3,500-7,000 \mathrm{~kJ} / \mathrm{kgTS}$. The decrease in solubility with higher energies may be explained by the combination and re-flocculation of the many substances that had been disintegrated (Bougrier et al. 2005; Naddeo et al. 2009). A further increase in the applied energy may cause these aggregates to re-solubilise, thus obtaining an asymptotic value. The asymptote appeared without the characteristic inflexion point in the unthickened sample (P1), which had a lower particulate matter content to solubilise (<2\% TS). Different authors have observed this asymptotic value with other treatments (Naddeo et al. 2009; Uma Rani et al. 2012b).

Table 2. Increases in tCOD with respect to initial values and evolution of the sCOD/tCOD ratio after ultrasound treatment and subsequent fermentation of primary sludge

\begin{tabular}{llcccccc}
\hline Sample & Treatment & \multicolumn{7}{c}{ Percentage increase with respect to initial tCOD } & \\
\hline & kJ/kgTS & Untreated & 3,500 & 7,000 & 10,500 & 14,000 & 21,000 \\
\hline P1 & Ultrasonication & 0 & 33 & 37 & 45 & 45 & 45 \\
& +Fermentation & 25 & 48 & 33 & 43 & 40 & 41 \\
P2 & Ultrasonication & 0 & 15 & 19 & 29 & 25 & 30 \\
& +Fermentation & -4 & 15 & 16 & 14 & 18 & 22 \\
P3 & Ultrasonication & 0 & 50 & 61 & 47 & 34 & 61 \\
& +Fermentation & 32 & 43 & 57 & 56 & 54 & 58 \\
P4 & Ultrasonication & 0 & -3 & 15 & 77 & 13 & 49 \\
& +Fermentation & -31 & 18 & 6 & 48 & -2 & 43 \\
\hline \multirow{5}{*}{ Sample } & Treatment & Evolution of sCOD/tCOD & & & & \\
\hline \multirow{4}{*}{ P1 } & kJ/kgTS & Untreated & 3,500 & 7,000 & 10,500 & 14,000 & 21,000 \\
\hline \multirow{4}{*}{ P2 } & Ultrasonication & 0.06 & 0.14 & 0.19 & 0.21 & 0.23 & 0.24 \\
& +Fermentation & 0.10 & 0.11 & 0.18 & 0.15 & 0.15 & 0.03 \\
& Ultrasonication & 0.13 & 0.17 & 0.21 & 0.17 & 0.17 & 0.18 \\
P3 & +Fermentation & 0.18 & 0.18 & 0.20 & 0.19 & 0.18 & 0.18 \\
& Ultrasonication & 0.02 & 0.06 & 0.06 & 0.07 & 0.07 & 0.06 \\
& +Fermentation & 0.09 & 0.12 & 0.11 & 0.12 & 0.13 & 0.12 \\
& Ultrasonication & 0.02 & 0.12 & 0.08 & 0.09 & 0.14 & 0.11 \\
& +Fermentation & 0.13 & 0.11 & 0.13 & 0.09 & 0.13 & 0.10 \\
\hline \multirow{4}{*}{ P4 } & & & & & & &
\end{tabular}


tCOD values increased when applying ultrasound (Table 2). This may be the result of water evaporation related to the thermal effect of ultrasound (Luste \& Luostarinen 2011), caused by the production of radicals, shear forces and friction generated by the dissipation of ultrasound waves. Therefore, the more pronounced the ultrasound irradiation (i.e. the greater the energy applied), the higher the temperature reached by the treated sludge. The rise in temperature also reinforces the disintegration caused by the treatment (Uma Rani et al. 2014), but it also has another effect on COD: the more volatile organic matter may be removed, as already reported by different researchers (Zhang et al. 2007; Naddeo et al. 2009; Erden \& Filibeli 2010). This was a reasonable explanation, as an intense odour was perceived from the highly irradiated samples. The problem caused by water evaporation was solved using the SCOD/tCOD ratio, which counterbalances the loss in solvent in both the soluble and insoluble COD in a similar way (Luste \& Luostarinen 2011). However, the effect of the selective removal of volatile components by ultrasonication leads to a decrease in this ratio.

The $\mathrm{SCOD} / \mathrm{tCOD}$ ratio of the treated samples was higher for all the applied energies. Therefore, the losses in water and volatile substances did not hinder the obtaining of a much more soluble substrate. The variation in $\mathrm{NH}_{4}{ }^{+}-\mathrm{N}$ concentration when applying ultrasound (Figure 2) followed a similar pattern to the COD, with the exception of sample $\mathrm{P} 4$, in which a decrease in $\mathrm{NH}_{4}{ }^{+}-\mathrm{N}$ was observed regardless of the energy applied. Figure 1 shows that the most pronounced decrease in solubilised matter occurred for this sample, especially for a $E_{s}$ of 7,000 kJ/kgTS, for which the lowest sCOD/tCOD ratio was obtained (0.08), as well as the maximum decrease in $\mathrm{NH}_{4}{ }^{+}-\mathrm{N}$. It is therefore highly likely that ammonium will be affected by re-aggregation of the solubilised matter.

Subsequent fermentation of the primary sludge after ultrasonication showed no clear pattern for SCOD. However, organic matter solubilisation appears to have continued during fermentation when no significant solubilisation was achieved by applying ultrasound. Similarly, if substantial solubilisation was achieved by applying ultrasound, the subsequent fermentation was accompanied by a certain degree of mineralisation of the organic matter.

What is unquestionable is that the effect of fermentation was much more influential in solubilising nitrogen than ultrasound was, regardless of the energy applied, as can be observed by the greater increase in $\mathrm{NH}_{4}{ }^{+} \mathrm{N}$ in the sample not treated by ultrasound. Biomolecules containing nitrogen (mainly proteins) were hence far less sensitive to ultrasound than to heating at $37^{\circ} \mathrm{C}$ for one day. 

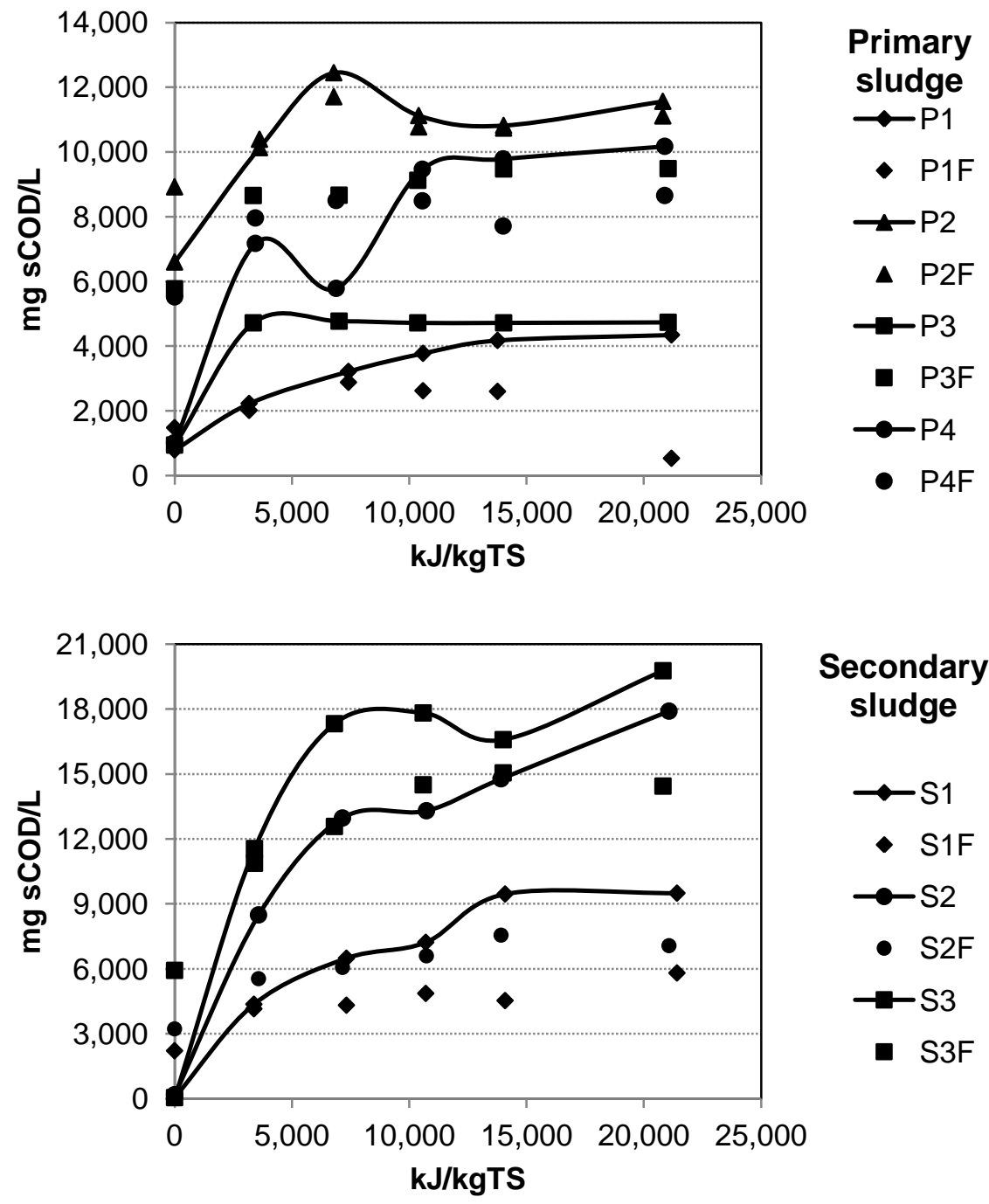

\section{Secondary sludge}<smiles>CC=[SiH2]</smiles>

- S1F<smiles>CC=[Se]</smiles>

- S2F

$\rightarrow-S 3$

- S3F

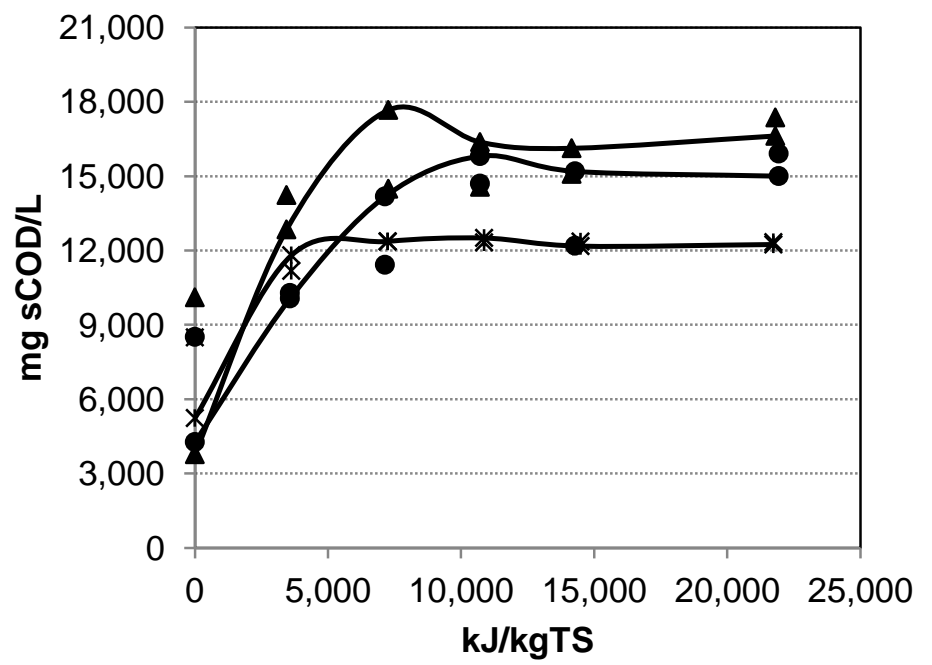

Mixed sludge<smiles>[M]C(C)C</smiles>

* M1F

$\rightarrow \mathrm{M} 2$

- M2F

$\rightarrow \mathrm{M} 3$

- M3F

Figure 1. Variation in SCOD with specific energy. " $F$ " denotes the subsequent fermentation ( $37^{\circ} \mathrm{C}$, 24 hours) after ultrasound treatment 


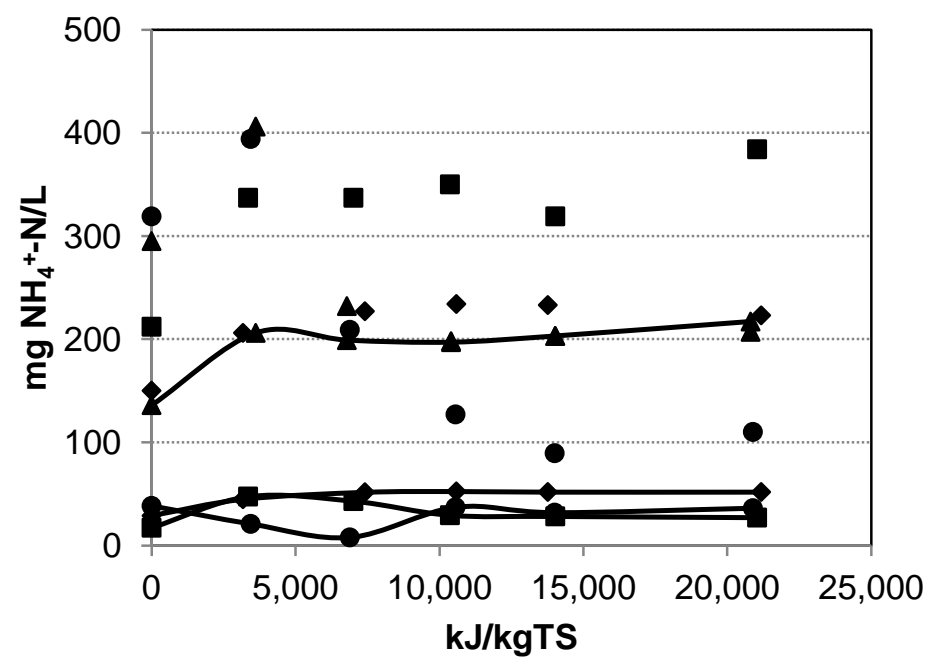

\section{Primary \\ sludge \\ $\rightarrow P 1$ \\ - P1F \\ $\rightarrow \mathrm{P} 2$}

- $\mathrm{P} 2 \mathrm{~F}$

$\rightarrow-P 3$

- P3F

$\rightarrow P 4$

- P4F

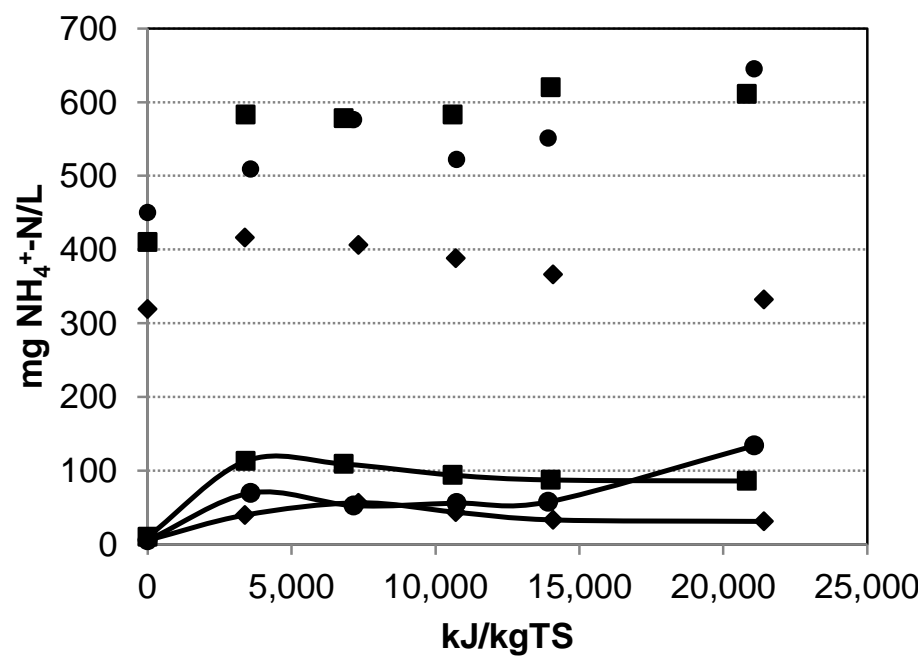

\section{Secondary}

sludge

$\rightarrow$ S1

- S1F

$\rightarrow$ S2

- S2F

$\rightarrow-S 3$

- S3F

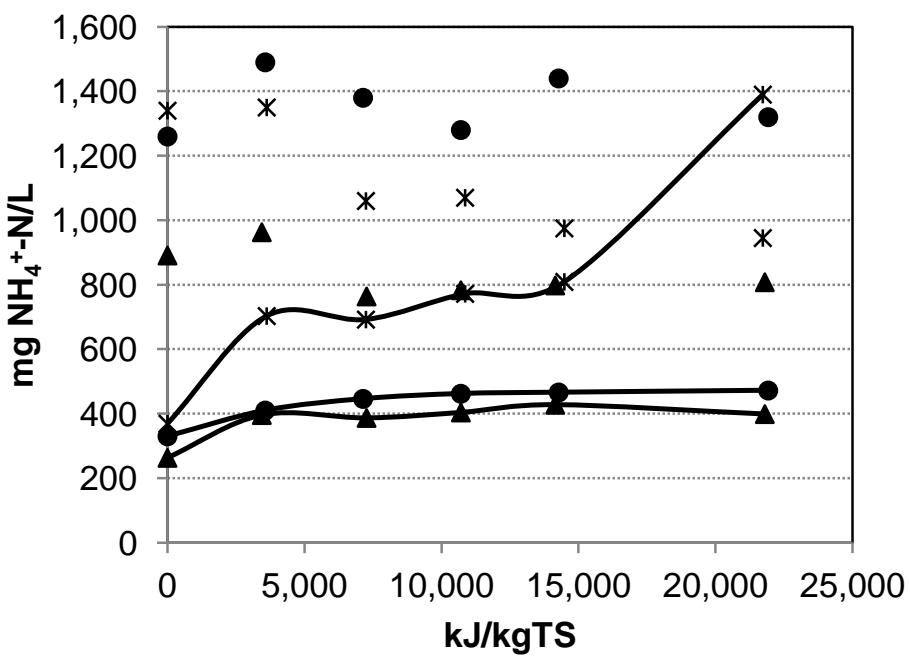

Mixed sludge

$\rightarrow$ - M1

* M1F

$\rightarrow \mathrm{M} 2$

- M2F

$\rightarrow \mathrm{M} 3$

- M3F

Figure 2. Variation in $\mathrm{NH}_{4}{ }^{+}-\mathrm{N}$ with specific energy. " $\mathrm{F}$ " denotes the subsequent fermentation ( $37^{\circ} \mathrm{C}$, 24 hours) after ultrasound treatment 


\section{Secondary sludge}

It is precisely in this sludge where sCOD increased the most (Figure 1), exceeding $19,000 \%$ in sample $\mathrm{S} 3$ for a $E_{s}=21,000 \mathrm{~kJ} / \mathrm{kgTS}$. This is not surprising, as ultrasound disruption has been mainly applied to treat secondary sludge (Carrère et al. 2010). The inflexion point in solubilisation that had been observed for 3,500-7,000 kJ/kgTS in the case of primary sludge appeared at 10,500-14,000 kJ/kgTS for secondary sludge.

An increase in tCOD was observed in two samples, S2 and S3, when applying ultrasound due to water evaporation (Table 3). However, tCOD decreased in sample S1 after the treatment. Bearing in mind that the tCOD/VS ratio in this sample was the lowest in all the secondary sludge samples (1.14) and the evolution of its sCOD/tCOD ratio always presented considerably higher values than those observed in the other samples, some volatile compounds may have been removed. This is in line with the slight reduction in the mass of dry solids reported by Uma Rani et al. (2014).

Table 3. Increases in tCOD with respect to initial values and evolution of the SCOD/tCOD ratio after ultrasound treatment and subsequent fermentation of secondary sludge

\begin{tabular}{llcccccc}
\hline Sample & Treatment & \multicolumn{7}{c}{ Percentage increase with respect to initial tCOD } \\
\hline S1 & kJ/kgTS & Untreated & 3,500 & 7,000 & 10,500 & 14,000 & 21,000 \\
\hline \multirow{4}{*}{ S2 } & Ultrasonication & 0 & -33 & -31 & -25 & -21 & -20 \\
& +Fermentation & -35 & -35 & -36 & -36 & -36 & -37 \\
& Ultrasonication & 0 & 18 & 38 & 28 & 45 & 33 \\
S3 & +Fermentation & -40 & -39 & -39 & -38 & -38 & -51 \\
& Ultrasonication & 0 & 61 & 68 & 71 & 34 & 59 \\
& +Fermentation & -25 & 18 & 23 & 18 & 4 & 34 \\
\hline \multirow{2}{*}{ Sample } & Treatment & Evolution of sCOD/tCOD & & & \\
\hline \multirow{2}{*}{ S1 } & kJ/kgTS & Untreated & 3,500 & 7,000 & 10,500 & 14,000 & 21,000 \\
\hline \multirow{3}{*}{ S2 } & Ultrasonication & 0.00 & 0.26 & 0.38 & 0.38 & 0.48 & 0.47 \\
& +Fermentation & 0.14 & 0.25 & 0.27 & 0.30 & 0.29 & 0.37 \\
& Ultrasonication & 0.00 & 0.17 & 0.22 & 0.25 & 0.24 & 0.32 \\
S3 & +Fermentation & 0.13 & 0.22 & 0.24 & 0.25 & 0.29 & 0.34 \\
& Ultrasonication & 0.00 & 0.18 & 0.26 & 0.26 & 0.31 & 0.32 \\
& +Fermentation & 0.20 & 0.24 & 0.26 & 0.31 & 0.37 & 0.27 \\
\hline
\end{tabular}

Secondary sludge also showed the highest improvements in terms of the hydrolysis of nitrogen compounds. Similar behaviour had already been reported elsewhere (Mao et al. 2004). This parameter does not seem to follow any clear pattern when the $E_{s}$ is increased. The highest concentrations of $\mathrm{NH}_{4}{ }^{+}-\mathrm{N}$ were obtained for 3,500, 7,000 and $21,000 \mathrm{~kJ} / \mathrm{kgTS}$. This variability could suggest that the re-aggregation of soluble substances also influenced the $\mathrm{NH}_{4}{ }^{+} \mathrm{N}$ concentration for intermediate values of $\mathrm{E}_{\mathrm{s}}$. 
The fermentation stage resulted in a reduction in SCOD and TCOD due to mineralisation of the organic matter. This decrease in SCOD was more pronounced when the SCOD following ultrasonication was higher. It may thus be concluded that the higher the SCOD in the ultrasonication stage, the faster the removal of SCOD in the fermentation stage. The upgrade in SCOD achieved in the untreated sample due to fermentation was once again far from the levels obtained in the samples treated by ultrasound disruption. Similar to the other types of sludge, the subsequent fermentation produced a much greater increase in $\mathrm{NH}_{4}{ }^{+}-\mathrm{N}$ than ultrasonication.

\section{Mixed sludge}

The application of ultrasound produced an increase in sCOD from 125\% to 340\% (Figure 1). The lowest increase was observed for the lowest energy input $(3,500 \mathrm{~kJ} / \mathrm{kgTS})$, whereas no marked differences were obtained for the rest of the $E_{s}$ in the 7,000-21,000 $\mathrm{kJ} / \mathrm{kgTS}$ range.

An increase in tCOD was observed (Table 4), being more pronounced for the highest $E_{s}$ due to the increase in temperature observed in the sample, which led to water evaporation. The rapid effect of sonication on SCOD is revealed in the SCOD/tCOD ratio. The energy inputs led to a two- to three-fold increase in this ratio compared to its initial value.

Table 4. Increases in tCOD and $\mathrm{NH}_{4}{ }^{+}-\mathrm{N}$ with respect to initial values and evolution of the sCOD/tCOD ratio after ultrasound treatment and subsequent fermentation of mixed sludge

\begin{tabular}{llcccccc}
\hline Sample & Treatment & \multicolumn{7}{c}{ Percentage increase with respect to initial tCOD } \\
\hline M1 & kJ/kgTS & Untreated & 3,500 & 7,000 & 10,500 & 14,000 & 21,000 \\
\hline \multirow{4}{*}{ M2 } & Ultrasonication & 0 & -1 & 9 & 8 & 24 & 16 \\
& +Fermentation & -12 & 1 & 6 & 10 & 2 & 7 \\
& Ultrasonication & 0 & 6 & 11 & 22 & 17 & 21 \\
M3 & +Fermentation & -2 & -4 & -2 & -4 & 17 & -3 \\
& Ultrasonication & 0 & 26 & 27 & 32 & 28 & 40 \\
& +Fermentation & 12 & 14 & 21 & 29 & 25 & 21 \\
\hline \multirow{2}{*}{ Sample } & Treatment & Evolution of sCOD/tCOD & & & \\
\hline \multirow{2}{*}{ M1 } & kJ/kgTS & Untreated & 3,500 & 7,000 & 10,500 & 14,000 & 21,000 \\
\hline \multirow{3}{*}{ M2 } & Ultrasonication & 0.11 & 0.25 & 0.24 & 0.24 & 0.20 & 0.22 \\
& +Fermentation & 0.20 & 0.23 & 0.24 & 0.23 & 0.25 & 0.24 \\
& Ultrasonication & 0.10 & 0.23 & 0.31 & 0.32 & 0.32 & 0.30 \\
M3 & +Fermentation & 0.21 & 0.26 & 0.29 & 0.38 & 0.26 & 0.40 \\
& Ultrasonication & 0.08 & 0.23 & 0.31 & 0.27 & 0.28 & 0.26 \\
& +Fermentation & 0.20 & 0.28 & 0.26 & 0.25 & 0.27 & 0.32 \\
\hline
\end{tabular}


The application of ultrasound increased the content in $\mathrm{NH}_{4}{ }^{+}-\mathrm{N}$. The energy input did not seem to have a strong effect on this parameter; a higher increase only being observed in sample M1 (up to $277 \%$ ) when applying the highest $E_{s}$. The subsequent fermentation generally produced a reduction in SCOD and tCOD due to losses in $\mathrm{CO}_{2}$, and a further increase in $\mathrm{NH}_{4}{ }^{+}-\mathrm{N}$.

The SCOD/tCOD ratio experienced slight variations after fermentation depending on the $E_{s}$; however, the variation reached a maximum for the highest $E_{s}$. This ratio was always higher than that obtained only by fermentation of the untreated sludge sample. The ratio increased approximately two-fold when fermenting the untreated sample compared to its initial value.

Summarising the results for the different sludge samples, it can be stated that the inflexion point in SCOD was observed in all three types of samples. Only in samples with low solids content and therefore low levels of organic matter to solubilise was this inflexion point barely appreciated. It was observed at lower energies for primary sludge than for secondary sludge, which would explain why the inflexion point was sometimes barely observed in mixed sludge.

\section{CONCLUSIONS}

The aim of this study was to obtain the optimum solubilisation of primary, secondary and mixed sludge after ultrasound irradiation (3,500-21,000 kJ/kgTS) and a subsequent fermentation stage ( 24 hours, $370 \mathrm{C}$ ). No addition of inoculum was required for the fermentation stage to occur. Consequently, microbial abatement by the applied energies did not inhibit bacterial activity in primary, secondary or mixed sludge.

An inflexion point in solubility was detected when applying ultrasound at different specific energies depending on the type of sludge (after 3,500-7,000 kJ/kgTS in primary sludge and after $10,500-14,000 \mathrm{~kJ} / \mathrm{kgTS}$ in secondary sludge). This was not so clearly observed in mixed sludge, the samples of which showed only slight variations in SCOD from $10,500 \mathrm{~kJ} / \mathrm{kgTS}$ onwards.

Some variations in tCOD during ultrasound treatment were due to the effect of temperature and removal of volatile compounds.

The effect of the treatment (both on SCOD and $\mathrm{NH}_{4}{ }^{+}-\mathrm{N}$ ) was clearly more pronounced when applied to secondary sludge than to the other types of sludge.

Temperature effects influenced the increases in $\mathrm{NH}_{4}{ }^{+}-\mathrm{N}$ much more than ultrasound.

Reductions in SCOD and $\mathrm{NH}_{4}{ }^{+}-\mathrm{N}$ were sometimes observed after fermentation. These may be due to metabolic removal of organic compounds and nitrogen ammonium and were more pronounced in mixed sludge. 


\section{ACKNOWLEDGEMENTS}

The research leading to these results has received funding from the European Union Seventh Framework Programme (FP7-ENV.2010.3.1.1-2 ENV) under Grant Agreement no. 265269. http://www.end-o-sludg.eu/

The authors are grateful for the comments from the anonymous reviewers which contributed to improving the quality of this paper.

\section{REFERENCES}

APHA, AWWA \& WEF 1998 Standard Methods for the Examination of Water and Wastewater. 20th edn, Washington DC, USA.

Appels L., Baeyens J., Degrève J. \& Dewil R. 2008 Principles and potential of the anaerobic digestion of waste-activated sludge. Progress in Energy and Combustion Science 34, 755-781.

Barjenbruch M. \& Kopplow O. 2003 Enzymatic, mechanical and thermal pre-treatment of surplus sludge. Advances in Environmental Research 7(3), 715-720.

Bougrier C., Carrère H. \& Delgenès J. P. 2005 Solubilisation of waste-activated sludge by ultrasonic treatment. Chemical Engineering Journal 106, 163-169.

Broderick G. A. 1987 Determination of protein degradation rates using a rumen in vitro system containing inhibitors of microbial nitrogen metabolism. British Journal of Nutrition 58, 463-475.

Carrère H., Dumas C., Battimelli A., Batstone D. J., Delgenès J. P., Steyer J. P. \& Ferrer I. 2010 Pre-treatment methods to improve sludge anaerobic degradability: A review. Journal of Hazardous Materials 183, 1-15.

Devlin D. C., Steves S. R. R., Dinsdale R. M. \& Guwy A. J. 2011 The effect of acid pretreatment on the anaerobic digestion and dewatering of waste activated sludge. Bioresource Technology 102, 4076-4082.

Elbeshbishy E., Aldin S., Hafez H., Nakhla G. \& Ray M. 2011 Impact of ultrasonication of hog manure on anaerobic digestability. Ultrasonics Sonochemistry 18, 164-171.

Erden G. \& Filibeli A. 2010 Ultrasonic pre-treatment of biological sludge: consequences for disintegration, anaerobic biodegradability, and filterability. Journal of Chemical Technology and Biotechnology 85, 145-150.

Eskicioglu C., Kennedy K. J. \& Droste R. L. 2006 Characterization of soluble organic matter of waste activated sludge before and after thermal pretreatment. Water Research 40, 3725-3736. 
Gayathri T., Kavitha S., Adish Kumar S., Kaliappan S., Yeom I. T. \& Rajesh Banu J. 2015 Effect of citric acid induced deflocculation on the ultrasonic pretreatment efficiency of dairy waste activated sludge. Ultrasonics Sonochemistry 22, 333-340.

Hasegawa S., Shiota N., Katsura K. \& Akashi A. 2000 Solubilization of organic sludge by thermophilic aerobic bacteria as a pretreatment for anaerobic digestion. Water Science and Technology 41(3), 163-169.

Kavitha S., Jayashree C., Adish Kumar S., Kaliappan S. \& Rajesh Banu J. 2014 Enhancing the functional and economical efficiency of a novel combined thermo chemical disperser disintegration of waste activated sludge for biogas production. Bioresource Technology $173,32-41$.

Kim D. J. \& Lee J. 2012 Ultrasonic sludge disintegration for enhanced methane production in anaerobic digestion: effects of sludge hydrolysis efficiency and hydraulic retention time. Bioprocess Biosystem Engineering 35, 289-296.

King R. O. \& Forster C.F. 1990 Effects of sonication on activated sludge. Enzyme and Microbial Technology 12, 109-115.

Luste S. \& Luostarinen S. 2011 Enhanced methane production from ultrasound pretreated and hygienized dairy cattle slurry. Waste Management 31, 2174-2179.

Mao T., Hong S. Y., Show K. Y., Tay J. H. \& Lee D. J. 2004 A comparison of ultrasound treatment on primary and secondary sludges. Water Science and Technology 50(9), 9197.

Marañón E., Negral L., Fernández-Nava Y. \& Castrillón L. 2013 Influence of conditioning agents and enzymic hydrolysis on the biochemical methane potential of sewage sludge. Water Science and Technology 68(7), 1622-1632.

More T. T. \& Ghangrekar M. M. 2010 Improving performance of microbial fuel cell with ultrasonication pre-treatment of mixed anaerobic inoculum sludge. Bioresource Technology 101, 562-567.

Nabarlatz D., Vondrysova J., Jenicek P., Stüber F., Font J., Fortuny A., Fabregat A. \& Bengoa C. 2010 Hydrolytic enzymes in activated sludge: Extraction of protease and lipase by stirring and ultrasonication. Ultrasonics Sonochemistry 17, 923-931.

Naddeo V., Belgiorno V., Landi M., Zarra T. \& Napoli R. M. A. 2009 Effect of sonolysis on waste activated sludge solubilisation and anaerobic biodegradability. Desalination 249, 762-767. 
Negral L., Marañón E., Fernández-Nava Y. \& Castrillón L. 2013 Short term evolution of soluble COD and ammonium in pre-treated sewage sludge by ultrasound and inverted phase fermentation. Chemical Engineering and Processing: Process Intensification 69, 44-51.

Pilli S., Bhunia P., Yan S., LeBlanc R. J., Tyagi R. D. \& Surampalli R. Y. 2011 Ultrasonic pretreatment of sludge: A review. Ultrasonics Sonochemistry 18, 1-18.

Salsabil M. R., Prorot A., Casellas M. \& Dagot C. 2009 Pre-treatment of activated sludge: Effect of sonication on aerobic and anaerobic digestibility. Chemical Engineering Journal 148, 327-335.

Show K. Y., Mao T. \& Lee D. J. 2007 Optimisation of sludge disruption by sonication. Water Research 41, 4741-4747.

Tchobanoglous G., Stensel H. D., Tsuchihashi R. \& Burton F. 2014 Wastewater Engineering: Treatment and Resource Recovery. McGraw-Hill Education. 5th International Edition, New York, USA.

Tyagi V. K., Lo S. L., Appels L. \& Dewil R. 2014 Ultrasonic treatment of waste sludge: a review on mechanisms and applications. Critical Reviews in Environmental Science and Technology 44, 1220-1288.

Ucisik A. S. \& Henze M. 2008 Biological hydrolysis and acidification of sludge under anaerobic conditions: The effect of sludge and origin on the production and composition of volatile fatty acids. Water Research 42, 3729-3738.

Uma Rani R., Kaliappan S., Adish Kumar S. \& Rajesh Banu J. 2012b Combined treatment of alkaline and disperser for improving solubilisation and anaerobic biodegradability of dairy waste activated sludge. Bioresource Technology 126, 107-116.

Uma Rani R., Adish Kumar S., Kaliappan S., Yeom I. T. \& Rajesh Banu J. 2012a Low temperature thermo-chemical pretreatment of dairy waste activated sludge for anaerobic digestion process. Bioresource Technology 103, 415-424.

Uma Rani R., Adish Kumar S., Kaliappan S., Yeom I. T. \& Rajesh Banu J. 2014 Enhancing the anaerobic digestion potential of dairy waste activated sludge by two step sonoalkalization pretreatment. Ultrasonics Sonochemistry 21, 1065-1074.

Xie B., Liu H. \& Yan Y. 2009 Improvement of anaerobic sludge by low-intensity ultrasound. Journal of Environmental Management 90, 260-264.

Zhang P., Zhang G. \& Wang W. 2007 Ultrasonic treatment of biological sludge: floc disintegration, cell lysis and inactivation. Bioresource Technology 98, 207-210. 